\title{
Glutamine Synthetase
}

\section{Factors Controlling Its Activity in the Developing Rat $^{1}$}

\author{
CHUNG WU \\ From the Department of Internal Medicine, The University of Michigan, Ann Arbor, Michigan
}

Received January 22, 1964

\begin{abstract}
The developmental changes in glutamine synthetase activity in rat liver and brain have been studied and shown to be different in the two tissues. The liver enzyme exhibited a fall in activity after birth, followed by a slow recovery and a rapid increase in activity for a short interval of time, before a gradual rise to the adult level in about 40 days. The brain enzyme raised its activity gradually and steadily right after birth until it reached the adult level in about 18 days.

The enzyme activity in the liver of developing rats appears to be affected by those compounds that also affect protein synthesis, ribonucleic acid synthesis, or deoxyribonucleic acid synthesis. When injected into young rats, puromycin, bL-p-fluorophenylalanine, ammonium lactate, actinomycin $\mathrm{D}$, and 8-azaguanine lowered the enzyme activity in liver, whereas Du-ethionine, cortisol, L-thyroxine, and 5-fluorouracil elevated it. The absence of effect of these compounds on the enzyme activity in vitro suggests that the changes observed may result from their effect on the amount of the enzyme formed in the liver. In most instances, the enzyme in the brain escaped the effect of these compounds.

With repeated injections of puromycin to block the synthesis of glutamine synthetase, the enzyme in the liver and testis, respectively, lost one half of its original activity in about 14 hours and 7.5 hours. A very slight decrease in the activity, however, occurred in the brain and kidney.
\end{abstract}

\section{INTRODUCTION}

The prenatal development of glutamyl transferase, an enzyme closely related to glutamine synthetase, has been studied in the chick embryo (2), and in the brain of the fetal pig and monkey (3). But the change in glutamine synthetase activity following birth of an animal has not been reported. The postnatal change in an enzyme activity in an animal may belong to one of the following patterns: (a) The enzyme activity is not detectable or very low at birth, but increases to the adult level very rapidly, such as tryptophan peroxidase in guinea pig liver (4). (b) The enzyme activity is negligible at birth, but reaches the adult

\footnotetext{
1 Paper II of this series described the intracellular localization of glutamine synthetase in rat liver (1).
}

level only gradually, such as 5-hydroxytryptophan decarboxylase in rat kidney (5). (c) The enzyme activity at birth attains or exceeds the adult level, such as tyrosine transaminase in rat liver (6). (d) The enzyme activity decreases following birth and then gradually increases to the adult level, such as glucose 6-phosphate dehydrogenase in rat liver (7). The pattern of change for a given enzyme may also depend on the species of the animal studied (8).

The pattern of change with age in glutamine synthetase activity in rat liver is similar to $(d)$ above, whereas that in rat brain resembles $(b)$. In addition, compounds producing different metabolic effects have been injected into the developing rat in an effort to understand the mechanisms by which the enzyme activity may be con- 
trolled. This paper describes these observations.

\section{EXPERIMENTAL PROCEDURE}

Rats of the Sprague-Dawley strain from several hours to 60 days of age were used. Infant rats of the same age but from different litters could have significantly different liver glutamine synthetase activities, although the enzyme activity varied relatively little among litter mates. Hence, rats from different litters served to obtain the mean value for the enzyme activity in a particular age group, so that the value obtained would be more representative. Both the lactating and the weanling rats received a laboratory chow. In the experiments where the in vivo effect of various conpounds on the enzyme activity was studied, litter mates always served as the control in each experiment. Most of the tonpounds tested were prepared in physiological saline, with $\mathrm{pH}$ adjusted to 7.2 , and injected intraperitoneally, except cortisol which was dissolved in sesame oil and given intramuscularly. Single daily injections of a test compound began when the animals reached 15 days of age and continued for 3 consecutive days. The controls received saline or sesame oil as the case may be. The animals were killed one day after the last injection. Deviations from this general plan occurred in a few instances; they will be noted.

In another series of experiments, puromycin dihydrochloride (Nutritional Biochemicals Corporation) was injected repeatedly into 24-day-old male rats to study the rates of breakdown of glutamine synthetase in different organs. These animals were killed from one to 7 hours following the initial injections of puromycin.

Glutamine synthetase activity and glutamine in the tissue homogenates were determined as before (9). One unit of the enzyme activity is defined as the amount of enzyme that will synthesize one micromole of $\gamma$-glutamyl hydroxamic acid in one hour at $37^{\circ} \mathrm{C}$. The method of Iowry et al. (10) served for determining the protein, with crystalline bovine albumin (Pentex, Ine.) as the standard.

\section{RESULTS}

\section{Developmental Changes}

Figure 1 shows the change in glutamine synthetase activity in liver of rats during the first 60 days of life. The enzyme activity has been expressed in four different ways, namely, units per milligram of protein (specific activity), units per gram of liver (tissue activity), units per liver (total ac-

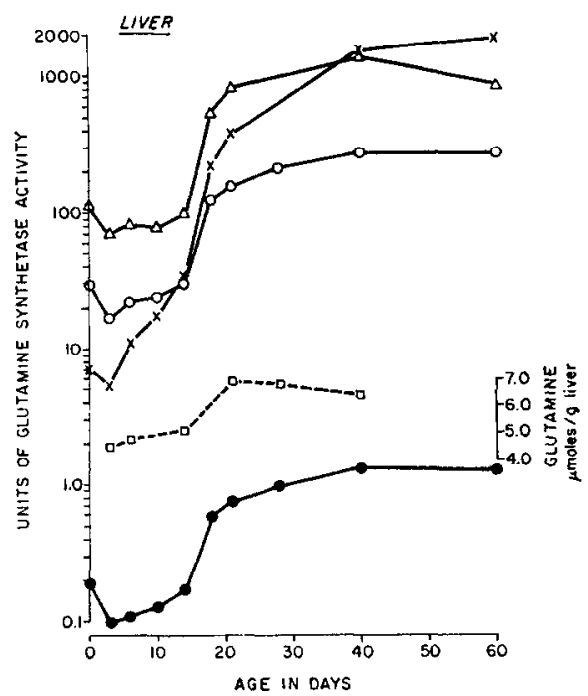

FIg. 1. The change in glutamine synthetase activity in liver of rats during the first 60 days of life. The enzyme activity, shown on the ordinate on a logarithmic scale, is expressed as units per milligram of protein (C), units per gram of tissue $(O)$, units per tissue $(X)$, and units per tissue per $100 \mathrm{gm}$ of body weight $(\triangle)$. The concentration of frce glutamine $(\square)$ is expressed in terms of micromoles per gram of tissue. Each point represents the average from 3 to 8 rats.

tivity), and units per liver per 100 grams of body weight, to take into account the rapidly increasing protein content of the tissue, tissue weight, and body weight during the period of observation. Since rats constituling a given age group came from different litters, the variation would be expected to be wider than if they had come from a single litter. The average deviation from the mean for the enzyme activity, expressed in any of the four ways, varied from 5 to $15 \%$ of the mean value. We can see that, in the liver, the enzyme activity showed a decrease soon after birth and reached its lowest point in about 3 days. The liver did not recover its neonatal loss of the enzyme activity until the fourteenth day after birth. The recovery during this period appeared to be a slow process. Once the enzyme had regained its activity at birth, however, a rapid increase ensued betwcen the fourteenth and the eighteenth days of life. After that, the enzyme activity gradually reached its adult level on about the 40th day. These 
observations show that the postnatal change in glutamine synthetase activity in rat liver undergoes four stages in the following order: an initial fall, a slow recovery, a rapid increase, and a gradual rise to a plateau.

Efforts have been made to understand the initial fall of the enzyme activity. Combining the liver homogenate from 3-dayold rats with that from 21-day-old rats always yielded an activity equal to the summed activities of the two homogenates, indicating that the lowering of the enzyme activity in the liver of 3-day-old rats was not due to an inhibitor. Prior incubation of the whole blood or serum from pregnant rats with the liver homogenate from 3-dayold rats at room temperature for 3 hours failed to raise the enzyme activity of the homogenate. The last observation appears to suggest that the loss of the enzyme activity in the 3-day-old rat may not result from the lack of a humoral factor in the maternal blood circulation.

The developmental change in the enzyme activity in brain (cerebrum), shown in Fig. 2, differed from that in liver in three aspects: (a) No initial loss of the enzyme activity occurred after birth. (b) The increase in the enzyme activity proceeded at a steady rate until the adult level was reached. (c) The enzyme in brain attained its adult level in 18 days after birth, in

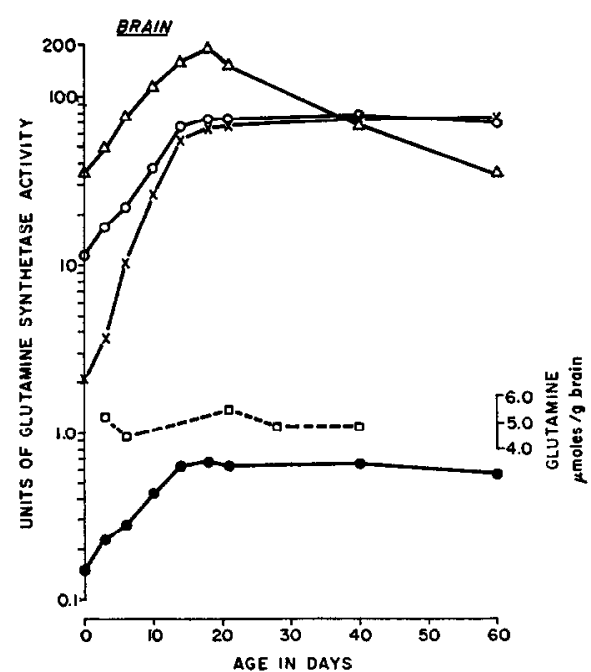

FIG. 2. The change in glutamine synthetase activity in brain of rats during the first 60 days of life. For explanation of symbols, see Fig. 1. contrast to the enzyme in liver which took about 40 days. These observations show a definite difference in the developmental change in the activity of one enzyme between two organs of the same animal.

Free glutamine in liver and brain has been determined also. The average deviation from the mean amounted to about $10 \%$ of the mean value for each age group. Comparisons of the concentration of free glutamine (Figs. 1 and 2) with glutamine synthetase activity in the same tissue show that the changes with age in these two parameters bore some correlation in the liver, but not in the brain.

The curves for specific activity, tissue activity, and total activity per $100 \mathrm{gm}$ of body weight exhibited a similar shape up to 40 days of age for liver and 18 days of age for brain. After that, the total activity per $100 \mathrm{gm}$ of body weight dropped in both tissues, showing a diminishing ratio of tissue weight to body weight.

\section{Responsiveness to Metabolic Alterations}

Compounds with different metabolic functions have been injected into 15-day-old rats to study their effects on glutamine synthetase activity. Animals of this age group were chosen because the highest rate of increase in the enzyme activity occurred in the succeeding days. Table I summarizes these findings. Puromycin produced the greatest inhibitory effect in vivo. With a dosage of $176 \mu \mathrm{g}$ per gram of body weight, it inhibited almost completely glutamine synthetase in liver following two intraperitoneal injections. On the other hand, adding puromycin to the reaction mixture to a final concentration of $390 \mu \mathrm{g}$ per milliliter did not decrease the enzyme activity of the liver. The result suggests that the decrease in the enzyme activity in vivo may represent a reduction in the amount of the enzyme in the tissue. The animals receiving the highest dosage of puromycin also lost body weight.

Of the two amino acid analogs tested, DL-ethionine increased the enzyme activity in liver, whereas DL-p-fluorophenylalanine decreased it. The decrease in the enzyme activity was associated also with a loss of body weight. Injecting ethionine in the same 
TABLE I

Effect of Various Compounds on Glutamine Synthetase Activity in Developing Rats

Fifteen-day-old rats received single daily intraperitoneal injections of the compounds for 3 consecutive days. Cortisol was given intramuscularly. The rats were killed one day after the last injection. Litter mates always served as the controls in each experiment. Exceptions are given in the accompanying footnotes. The enzyme activity is expressed as a percentage of the control value. The average values for liver and brain from a total of 18 control rats gave, respectively, $95.6 \pm 20.4$ and $80.0 \pm[12.0$ (standard deviation) units per gram of tissue.

\begin{tabular}{|c|c|c|c|c|c|}
\hline \multirow{2}{*}{ Treatment } & \multirow{2}{*}{$\begin{array}{l}\text { Number } \\
\text { of rats }\end{array}$} & \multirow{2}{*}{$\begin{array}{l}\text { Dosage, per gm } \\
\text { of body weight }\end{array}$} & \multirow{2}{*}{$\begin{array}{c}\text { Relative } \\
\text { change in } \\
\text { body } \\
\text { weight } \\
\text { (gm/day) }\end{array}$} & \multicolumn{2}{|c|}{ Glutamine synthetase activity (\%) } \\
\hline & & & & Liver & Brain \\
\hline None & 18 & & $(0.0)$ & $(100.0)$ & $(100.0)$ \\
\hline Puromycin $\cdot 2 \mathrm{HCl}$ & $3^{b}$ & $176 \mu \mathrm{g}$ & -2.9 & $5.4 \pm 0.4^{h}$ & $80.2 \pm 5.4$ \\
\hline Puromycin $\cdot 2 \mathrm{HCl}$ & 3 & $44 \mu \mathrm{g}$ & -0.3 & $83.6 \pm 3.3$ & $111 \pm 4.8$ \\
\hline Puromycin $\cdot 2 \mathrm{HCl}$ & 3 & $17.6 \mu \mathrm{g}$ & -0.1 & $107 \pm 6.3$ & $97.9 \pm 2.9$ \\
\hline DL-Ethionine & 3 & $0.8 \mu$ mole & -0.6 & $139 \pm 7.3$ & $97.1 \pm 6.0$ \\
\hline DL-Ethionine & 4 & $0.3 \mu$ mole & -0.4 & $148 \pm 2.0$ & $99.4 \pm 6.9$ \\
\hline $\begin{array}{l}\text { DL- } p \text {-Fluoro- } \\
\text { phenylalanine }\end{array}$ & 3 & $2.2 \mu$ moles & -3.1 & $66.4 \pm 8.8$ & $104 \pm 4.5$ \\
\hline $\begin{array}{l}\text { DL-p-Fluoro- } \\
\text { phenylalanine }\end{array}$ & 2 & $0.3 \mu \mathrm{mole}$ & -0.4 & $96.6 \pm 4.6$ & $99.6 \pm 0.4$ \\
\hline Cortisol & 3 & $5 \mu \mathrm{g}$ & +0.3 & $163 \pm 10.3$ & $97.0 \pm 3.2$ \\
\hline Thyroxine & 3 & $1 \mu \mathrm{g}$ & -0.1 & $169 \pm 7.7$ & $100 \pm 7.5$ \\
\hline Ammonium lac- & 2 & $2.1 \mu$ moles & +0.1 & $86.0 \pm 6.5$ & $107 \pm 9.6$ \\
\hline $\begin{array}{l}\text { Ammonium lac- } \\
\text { tate }\end{array}$ & $3^{\circ}$ & $2.1 \mu$ moles & -0.2 & $67.3 \pm 5.9$ & $102 \pm 9.3$ \\
\hline $\begin{array}{l}\text { DL-allo- } \delta-\mathrm{Hy}- \\
\text { droxylysine. } \\
\mathrm{HCl}\end{array}$ & $3^{d}$ & 3 umoles & & $98.8 \pm 2.9$ & \\
\hline $\begin{array}{l}\text { Sodium gluta- } \\
\text { mate }\end{array}$ & 3 & $10 \mu$ moles & -0.2 & $104 \pm 4.0$ & $106 \pm 5.3$ \\
\hline Deoxyadenosine & 4 & $0.9 \mu$ mole & -0.5 & $96.5 \pm 16.2$ & $97.0 \pm 0.9$ \\
\hline 5-Fluorouracil & $2^{e}$ & $0.5 \mathrm{mg}$ & -2.8 & $141 \pm 4.0$ & $78.0 \pm 6.0$ \\
\hline 5-Fluorouracil & 2 & $0.5 \mathrm{mg}$ & -4.1 & $117 \pm 0.0$ & $99.3 \pm 7.2$ \\
\hline 5-Fluorouracil & $2^{f}$ & $0.2 \mathrm{mg}$ & -8.3 & $122 \pm 17.0$ & $110 \pm 8.0$ \\
\hline 8-Azaguanine & 4 & $0.3 \mu$ mole & -1.7 & $76.0 \pm 4.4$ & $114 \pm 6.1$ \\
\hline 2-Thiouracil & 4 & $0.4 \mu \mathrm{mole}$ & -0.2 & $90.5 \pm 9.2$ & $107 \pm 4.7$ \\
\hline Actinomycin D & $3^{f, g}$ & $1 \mu \mathrm{g}$ & -6.3 & $48.7 \pm 5.3$ & \\
\hline Actinomycin $\mathrm{D}$ & $2^{f}$ & $0.5 \mu \mathrm{g}$ & -7.0 & $73.1 \pm 6.2$ & $103 \pm 1.0$ \\
\hline
\end{tabular}

a The average difference in body weight between the treated and the control rats.

${ }^{b}$ The experiment was terminated one day after the second injection, when the animals appeared very sick. On autopsy the gastrointestinal tract was yellow, and the abdominal cavity had a foul odor.

¿ The animals received one additional (fourth) injection 4 hours before saorifice.

${ }^{d}$ 'T'wenty-one-day-old rats weighing about $47 \mathrm{gm}$ were used in this experiment which lasted 4 days.

- The animals were killed 6 hours after the last injection.

$f$ Twenty-five-day-old male rats weighing about $65 \mathrm{gm}$ were used.

- The experiment was terminated one day after the second injection, when two other animals had died, and one was dying.

${ }^{h}$ The value following the \pm sign is the average deviation from the mean.

dosage to adult male rats, however, did not increase the enzyme activity in liver. When ethionine or $p$-fluorophenylalanine was added to the reaction mixture to a final concentration of 2.2 or $5.5 \mathrm{~m} M$, respectively, neither compound affected the enzyme activity of rat liver.

Both cortisol and thyroxine caused a 
significant increase in glutamine synthetase activity in infant rat liver. Injecting cortisol, however, in a similar dosage to adult rats did not result in an increase in the enzyme activity in liver. Thyroxine, when added to the reaction mixture to a final concentration of $11 \mu \mathrm{g}$ per milliliter, showed no effect on the enzyme activity.

The liver weight of infant rats receiving DL-ethionine, cortisol, or thyroxine was the same as that of the control rats. Hence, the increase in the enzyme activity in the liver of these injected rats can be attributed to an increase in the amount of the enzyme in the liver.

Ammonium lactate decreased the enzyme activity in liver. The dosage used was one fourth of $\mathrm{LD}_{50}$ (11). A further lowering of the enzyme activity occurred 4 hours after injesting one additional dose of the compound to the rat.

DL-allo- $\delta$-Hydroxylysine, which inhibited glutamine synthetase in vitro in a variety of tissues (9), did not affect the activity in vivo. Daily urine specimens from these rats were collected before and during the experimental period. With the method of Chinard (12) and a chromatographic procedure (13), about $40 \%$ of the hydroxylysine injected was found in the urine in a 24 -hour period. The relatively rapid excretion of the compound might account for its ineffectiveness in vivo.

Sodium glutamate exerted no effect on glutamine synthetase activity in liver. Glutamine, injected intraperitoneally into adult male rats in a dosage of $7 \mu$ moles per gram of body weight twice daily for 5 consecutive days, did not change the enzyme activity in either the liver or the brain.

Injecting the analogs of purines and pyrimidines gave varied effects on the liver enzyme. Deoxyadenosine, an inhibitor of $\mathrm{DNA}^{2}$ synthesis (14), produced no effect on the enzyme activity. But 5-fluorouracil, another inhibitor of DNA synthesis (15), increased it. The increase in the enzyme activity took place, while the animals were losing body weight from receiving the compound. The result expressed in either specific

\footnotetext{
${ }^{2}$ Abbreviations: DNA, deoxyribonucleic acid; RNA, ribonucleic acid.
}

activity or tissue activity shows a similar increase. Adding 5-fluorouracil, however, to the reaction mixture to a final concentration of $1.7 \mathrm{mg}$ per milliliter had no effect on the enzyme activity. On the other hand, the enzyme activity decreased in the liver of rats receiving 8-azaguanine.

Recently, Reich et al. (16) have shown that actinomycin D inhibits RNA synthesis in mammalian cells. The compound was extremely toxic; a dosage of $1 \mu \mathrm{g}$ per gram of body weight sufficed to kill the rat in 2 days following two intraperitoneal injections. Actinomycin $\mathrm{D}$ also caused the animals to lose body weight. Glutamine synthetase activity dropped considerably in the liver of these rats. On the other hand, actinomycin D at a concentration of $3 \mu \mathrm{g}$ per milliliter of the reaction mixture did not decrease the enzyme activity in vitro.

The results in Table I also show that the enzyme in rat brain (cerebrum) has resisted most efforts to change its activity. When puromycin inhibited almost completely the enzyme in liver, it merely lowered the enzyme activity in brain by $20 \%$. The amino acid analogs, the hormones, ammonium lactate, 5-fluorouracil, 8-azaguanine, and actinomycin $\mathrm{D}$ failed to bring about a definite change in the brain enzyme despite their effect on the liver enzyme. The results, in general, emphasize an inertness of the brain enzyme and a responsiveness of the liver enzyme to metabolic alterations.

\section{Breakdown of Glutamine Synthetase}

Puromycin inhibited in vivo the synthesis of protein from amino acids in mammalian liver (17). This observation taken in conjunction with the inhibition by this compound of glutamine synthetase in rat liver made it possible to study the breakdown of this enzyme in rat tissues. On the assumption that the dosage of puromycin injected into the rat was sufficient to block completely the synthesis of the enzyme, the decrease in the enzyme activity with time would indicate the rate of breakdown of the enzyme. Figure 3 shows the results of such an approach. The fall in glutamine synthetase activity during the multiple injections of puromycin into 24-day-old rats has been 
followed in the four organs possessing the enzyme activity, namely, the brain, liver, kidney, and testis (9). Consistent with the results shown in Table $I$, the brain enzyme maintained its normal activity throughout the experimental period. The kidney enzyme exhibited a very slight decline only. The enzyme activity in liver, though fluctuating, showed a definite fall. Thus, if a line is drawn in between these points (Fig. 3) and extrapolated, it would indicate that, in about 14 hours, the enzyme activity would have been reduced to one half of its original value at hour zero. The result calculated here can be approximate only because of the fluctuation of the enzyme activity and the assumption that the decline proceeded linearly. A similar estimate yielded about 7.5 hours for the enzyme in testis. Hence, the

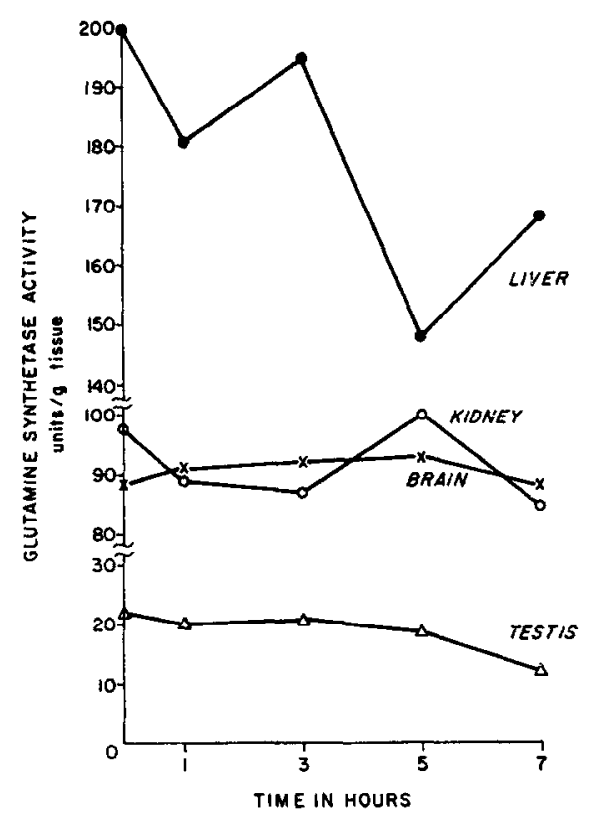

FIg. 3. Rates of breakdown of glutamine synthetase in rat liver ( brain $(X--X)$, and testis $(\triangle-\triangle)$. Twentyfour-day-old male rats weighing about $60 \mathrm{gm}$ received $3 \mathrm{mg}$ of puromycin dihydrochloride $(\mathrm{pH}$ adjusted) in each intraperitoneal injection given at $0,2,4$, and 6 hours, and were killed at $1,3,5$, and 7 hours after the first injections. Each point represents the average from 4 to $7 \mathrm{rats}$. The average deviations from the mean values at $0,1,3,5$, and 7 hours for the liver were $26.0,9.2,8.4,2.7$, and 7.2 , respectively; those for the testis were $1.0,1.8,1.7$, 1.7 , and 1.0 , respectively. turnover rates of the enzyme in the liver and testis were very much different. The very slight decrease in the enzyme activity observed with the brain and kidney may result from very low turnover rates of the enzyme in these tissues, or it may indicate that these tissues are not readily permeable to puromycin.

The per cent loss of the enzyme activity in liver 48 hours after injecting the highest dosage of puromycin into 15-day-old rats, shown in Table $I$, approximated a rate of loss of one half the enzyme activity in every 12 hours. This rate was close to the rate of breakdown calculated from the results obtained with 24-day-old rats, shown in Fig. 3. Perhaps, the rates of breakdown of the enzyme in rats of different age groups vary little; the changes seen in Fig. 1 may actually represent the varied rates of synthesis of the enzyme with age.

\section{DISCUSSION}

The present study shows that the activity of glutamine synthetase in vivo can be controlled by a number of compounds with varied metabolic properties. Since these compounds exerted no effect on the enzyme activity in vitro, the results suggest that the change in the activity in vivo may represent a corresponding change in the amount of the enzyme in the tissue.

Three kinds of metabolic alterations appear to affect the synthesis of the enzyme: (a) alterations in protein synthesis, (b) alterations in RNA synthesis, and (c) alterations in DNA synthesis. To the first kind belongs the effect of puromycin and of $p$-fluorophenylalanine. Both compounds inhibit protein synthesis in vivo. Their administration has caused loss of body weight in the developing rat. Cohen et al. (18) have suggested the synthesis of inactive enzyme by yeast cells in the presence of $p$-fluorophenylalanine. This possibility may also be considered in the rat liver.

Sokoloff et al. $(19,20)$ have shown that thyroxine stimulates amino acid incorporation into protein. Metzenberg et al. (21) have presented evidence showing the induction by thyroxine of de novo synthesis of carbamyl phosphate synthetase in tadpoles. These two observations may serve to ex- 
plain the elevation of glutamine synthetase activity by thyroxine in the developing rat.

Cortisone administration stimulates the incorporation of precursors into liver RNA in vivo (22). The cortisol-mediated increase in glutamine synthetase activity appears to result from an increase in the de novo synthesis of RNA. This mediation, however, seems to be limited to the synthesis of the enzyme in the developing rat, inasmuch as cortisol becomes ineffective in raising the enzyme activity in the adult rat where the maximal level of the enzyme has been reached. The dependence of the developmental increase in glutamine synthetase on RNA synthesis is also evident from the inhibitory effect of actinomycin D on the enzyme activity. Recently, Greengard et al. (23), and Nemeth (24) have demonstrated the relation of RNA synthesis to the formation of certain enzymes during development.

In contrast to inhibitors of protein synthesis or of RNA synthesis, which inhibiled glutamine synthetase, inhibitors of DNA synthesis did not decrease the synthetase activity; some of them increased it. Like cortisol, ethionine showed its stimulatory effect on the liver enzyme of developing rats but not that of adult rats. But the mechanism underlying the stimulation by ethionine probably resembles that by 5-fluorouracil, since, like 5-fluorouracil, ethionine also inhibits DNA synthesis in vivo (25). The relation of DNA synthesis to the formation of glutamine synthetase will be considered further in the following paper.

The dosage of puromycin used to block the synthesis of glutamine synthetase was about $62 \%$ of that used by Nemeth (24) to obtain the turnover rate of tryptophan pyrrolase. The rate of breakdown of the synthetase estimated in this study should be considered approximate, since how completely puromycin blocked the synthesis has not been ascertained.

Glutamine synthetase is not repressible by glutamine in the rat, although repression by glutamine of glutamyl transferase in mammalian cell cultures has been reported (26). The synthetase is also not inducible by glutamate or ammonia. Conversely, injecting ammonia lowered the enzyme ac- tivity, although Duda and Handler (27) showed that, within 30 minutes, $80 \%$ of the intravenously administered ammonia was converted to glutamine in the rat.

\section{ACKNOWLEDGMENTS}

The author is indebted to Dr. Clement A. Stone, Merck Institute for Therapeutic Research, and to Dr. W.E. Scott, Hoffmann-La Roche Inc., respectively, for generously donating the actinomycin $D$ and 5 -fluorouracil used in this investigation.

This work was supported in part by research grants, CA-01719 and AM-07319, from the National Cancer Institute and the National Institute of Arthritis and Metabolic Diseases, U. S. Public Health Service.

\section{REFERENCES}

1. Wu, C., Biochim. Biophys. Acta 77, 482 (1963).

2. Rudnick, D., Mela, P., and Waelsch, H., J. Exptl. Zool. 126, 297 (1954).

3. Jolley, R. L., and LabBy, D. H., Arch. Biochem. Biophys. 90, 122 (1960).

4. Nemeth, A. M., and Nachmias, V. T., Science 128, 1085 (1958).

5. Huang, I., Tannenbaum, S., and Hsia, D. Y.-Y., Nature 186, 717 (1960).

6. Aumrbach, V. H., and Waisman, H. A., $J$. Biol. Chem. 234, 304 (1959).

7. Stevens, L., Comp. Biochem. Physiol. 6, 129 (1962).

8. Nemeth, A. M., J. Biol. Chem. 234, 2921 (1959).

9. Wu, C., Comp. Biochem. Physiol. 8, 335 (1963).

10. Lowry, O. H., Rosebrough, N. J., Farr, A. L., and Randall, R. J., J. Biol. Chem. 193, 265 (1951).

11. Greenstein, J. P., Winitz, M., Gullino, P., Birnbaum, S. M., and Otey, M. C., Arch. Biochem. Biophys. 64, 342 (1956).

12. Chinard, F. P., J. Biol. Chem. 199, 91 (1952).

13. Wu, C., And BAUer, J. M., Cancer Res. 20, 818 (1960).

14. Maley, G. F., and Maley, F., J. Biol. Chem. 235, 2964 (1960).

15. Danneberg, P. B., Montag, B. J., and Hëidelaerger, C., Cancer Res. 18, 329 (1958).

16. Reich, E., Franklin, R. M., Shatkin, A. J., and Tatum, E. L., Science 134, 556 (1961).

17. Nemeth, A. M., and de la Haba, G., J. Biol. Chem. 237, 1190 (1962).

18. Cohen, G. N., Halvorson, H. O., and 
Spiegelman, S., in "Microsomal Particles and Protein Synthesis" (R. B. Roberts, ed.), Pergamon Press, New York, 1958, p. 100.

19. Sokoloff, L., Kaufman, S., Camprell, P. L., Francis, C. M., and Gelboin, H. V., $J$. Biol. Chem. 238, 1432 (1963).

20. Michels, R., Casun, J., And Sokoloff, L., Science 140, 1417 (1963).

21. Metzenberg, R. L., Marshali, M., Paik, W. K., AND Cohen, P. P., J. Biol. Chem. 236, 162 (1961).
22. Feigelson, M., Gross, P. R., and Feignlson, P., Biochim. Biophys. Acta 55, 495 (1962).

23. Greengard, O., Smith, M. A., and ACs, G., J. Biol. Chem. 238, 1548 (1963).

24. Nеметн, A. M., J. Biol. Chem. 237, 3703 (1962).

25. Schneider, J. H., Cassir, R., and ChordiKIaN, F., J. Biol. Chem. 235, 1437 (1960).

26. Paul, J., and Fottrell, P. F., Biochim. Biophys. Acta 67, 334 (1963).

27. Duda, G. D., and Handler, P., J. Biol. Chem. 232, 303 (1958). 